\title{
Instauração de um lugar de pesquisa, de uma posição pesquisadora - tributo a Eni Orlandi ${ }^{1}$
}

\author{
Instauration d'un lieu de recherche, d'un position de chercheur - un hommage à \\ Eni Orlandi
}

Claudia Castellanos Pfeiffer ${ }^{2}$

Universidade Estadual de Campinas

\begin{abstract}
- RESUMO: Este artigo faz uma homenagem à Eni Orlandi, professora, pesquisadora e orientadora no espaço teórico da Análise de Discurso (AD), tendo sido ela a responsável pela institucionalização e pelos desdobramentos heurísticos desta teoria no Brasil, construindo possibilidades para que a $\mathrm{AD}$ se formulasse como teoria, como disciplina e como área de conhecimento. Esta homenagem se materializa pela tessitura por entre alguns pontos de ancoragem de meu percurso de construção de um lugar para a pesquisa e para a posição pesquisadora instaurado na relação com Eni Orlandi. Uma forma de escuta desse percurso, um modo de retorno a esse/desse percurso, um gesto de homenagem.
\end{abstract}

- PALAVRAS-CHAVE: Eni Orlandi. Análise de Discurso. Homenagem.

- RÉSUMÉ: Cet article est un hommage à Eni Orlandi, professeur, chercheur et directeur de recherches dans l'espace théorique de l'analyse du discours (AD). Orlandi est responsable pour l'institutionnalisation et pour des conséquences heuristiques de cette théorie au Brésil. Elle a creé des possibilités de construction pour l'AD pouvoir être formuler comme théorie, comme discipline et ainsi comme domaine de la connaissance. Cet hommage est matérialisé par la couture à travers certains points d'ancrage de mon parcour de la construction d'un lieu de recherche et d'une position chercheur établies dans ma relation avec Eni Orlandi. Une façon d'écouter cette voie, un retour à cet/de cet chemin, un geste d'hommage.

- MOTS-CLÉS: Eni Orlandi. Analyse du Discours. Hommage.

Em um momento importante e emotivo como este, escolhi fazer minha homenagem a Eni Orlandi de modo a percorrer com ela alguns lugares fundantes de meu percurso intelectual que se inicia com uma questão de pesquisa ancorada no espaço escolar. Eni Orlandi sempre esteve a meu lado, em meus trajetos, e foi ela quem me abriu espaço para que eu conseguisse, na linguística e enquanto linguista, trabalhar as questões que me incomodavam ainda no final de minha graduação. Com ela, instaurei um lugar de pesquisa e tive condições de produção para construir minha posição pesquisadora. Eni era minha leitura de cabeceira, minha professora e, um pouco mais adiante, minha orientadora, minha interlocutora. Com ela fui formando meu arquivo de leitura discursiva, conhecendo diferentes autores, aprendendo análise de discurso, aprendendo a ler discursivamente. Com ela, comecei a ler Pêcheux. Um privilégio.

Quando conheci Eni, me inquietava com as críticas à qualidade dos alunos como leitores e autores de textos. Não me satisfazia com respostas deterministas que relacionavam as condições socio-econômicas ao rendimento escolar, pelo simples fato

1 Texto apresentado no V Encontro em Análise de Discurso: estudos Orlandianos/III Encontro Nacional em Semântica e Análise de Discurso: Marcha, Identidade e Fronteira, promovido pela UEMS e UNEMAT, ocorrido entre os dias 07 e 09 de junho de 2017, no Campus de Campo Grande/UEMS.

2 Doutora em Linguística pela UNICAMP. Labeurb/Nudecri/Unicamp. claupfe@gmail.com 
de que as dificuldades de leitura e de escrita eram tema de debate em qualquer escola. Também não me apaziguava com a ideia de que as técnicas de ensino estavam equivocadas porque, à parte toda e qualquer didática, em uma mesma sala de aula há alunos tidos como aqueles que escrevem e leem bem e outros considerados péssimos.

Em meio a essa inquietação ainda muito ingênua, aprendi nas primeiras aulas de Eni que o problema só poderia estar em algo menos visível, fruto do trabalho simbólico da ideologia. E foi o meu encontro com a Análise do Discurso (AD), com Eni Orlandi, que me proporcionou pensar discursivamente sobre essa questão, levando-me a caminhos que foram se desdobrando em diferentes e gratificantes trajetos acadêmicos e institucionais.

Se Eni é uma professora e uma orientadora extraordinária, não menos é sua liderança intelectual na formação de grupos e de áreas do conhecimento. Contemporânea de seu tempo, inquieta e desbravadora, Eni Orlandi instituiu a Análise de Discurso, como teoria, disciplina e área de conhecimento no Brasil. Com fôlego invejável, configurou mais duas áreas sob a sustentação teórica da análise de discurso: História das Ideias Linguísticas e Saber Urbano e Linguagem. Formou quadros espalhados por todo o território brasileiro; foi fundamental na configuração do Instituto de Estudos da Linguagem da Unicamp e responsável pela criação do Laboratório de Estudos Urbanos da Unicamp, nessa mesma universidade, e pelo Programa de PósGraduação em Ciências da Linguagem da Univás.

Em cada um desses movimentos, que são, a um só tempo, intelectuais, acadêmicos, científicos e institucionais, Eni sempre propôs projetos de pesquisa e sempre formou grupos com seus alunos e orientandos de modo generoso e formador. Tive a enorme oportunidade de estar inserida de modo muito próximo em seu percurso de institucionalização da História das Ideias Linguísticas e do Saber Urbano e Linguagem. Áreas em que atuo enquanto desdobramentos de meu percurso inicial que aqui compartilho com vocês como um modo singelo de homenagem a Eni Orlandi.

Volto então a esse percurso, no qual eu me perguntava sobre a natureza do funcionamento que produzia a dificuldade dos alunos de interpretarem e escreverem textos.

Conforme me aventurava por leituras teóricas e pelas experiências de sala de aula - como professora ou como observadora -, foi ficando cada vez mais forte para mim que o problema é ideológico e da ordem do simbólico. Isso porque aprendia com Eni Orlandi a necessidade teórica de assumirmos uma tripla negação: a língua não é reflexo dos problemas sociais, econômicos ou culturais; a língua não é um instrumento de controle de sujeitos sobre sujeitos; a língua não é exterior ao sujeito.

Lendo e ouvindo Eni Orlandi, compreendi que a língua é constitutiva do sujeito, o que significa dizer que sujeito e linguagem constroem-se mutuamente: ou, dito de outro modo, que diferentes posições-sujeito implicam em diferentes discursividades. Foi assim que fui me encaminhando para a compreensão de um dos pilares da Análise de Discurso: não há língua sem sujeito e não há sujeito sem ideologia. Mas era preciso entender o estatuto da ideologia aí. Foi com Eni Orlandi que pude compreender que a ideologia é uma "prática significativa", diferentemente de uma posição sociológica mais geral de ideologia como conjunto de representações, ou como ocultação da realidade. Como a autora formula, "a ideologia está na base da necessidade de interpretação, é efeito da relação do sujeito com a língua e a história” (ORLANDI, 1996:48). Para Orlandi, na língua, o efeito ideológico fundante está na transparência dos sentidos, como se fossem colados às palavras; já, na história, a ideologia está na tomada do fato pelo dado: ou seja, a evidência do produto (ORLANDI, 1993d). É pensando assim que, para a autora, o discurso "é essa conjugação necessária da língua com a 
história que produz a impressão de realidade. [e continua a autora, afirmando que] $\mathrm{O}$ gesto da formulação é o gesto ideológico mínimo, o que consuma o imaginário no sujeito" (ORLANDI, 1996:40)

Frente a isso e para conseguir me situar diante de meu objeto de pesquisa, precisei também compreender o lugar da interpretação na Análise de Discurso. Porque eu precisava compreender o que está envolvido na prática da interpretação escolar e porque eu precisava aprender a interpretar discursivamente. E para isso foi fundamental a formulação de Orlandi (1993d) da leitura como um dispositivo teórico. E a diferença de pensar o funcionamento da leitura intermediado pelo dispositivo ideológico.

Para entender estas diferenças, percorri as formulações da autora em torno de sua compreensão sobre o funcionamento da interpretação na linguagem. Para Orlandi, o trabalho da interpretação se encontra onde se dá o deslize dos sentidos, onde língua e história se ligam pelo equívoco. E, ao mesmo tempo, é pelo trabalho ideológico que há o trabalho da interpretação.

Por isso, Eni Orlandi aponta a necessidade de distinguir interpretação (entendida como gesto de atribuição de sentido) de compreensão (enquanto um gesto de análise de como um objeto simbólico produz sentido) (ORLANDI, 1987). Nesta reflexão da autora, interpretar é sempre uma intervenção do sujeito no mundo: é um ato simbólico, uma prática discursiva: aquilo que ela nomeará de gesto de interpretação. Este gesto pode estar mediado pelo dispositivo teórico ou pelo dispositivo ideológico.

$\mathrm{Na}$ mediação pelo dispositivo ideológico, mediação própria de nossas práticas linguajeiras, há o funcionamento da evidência do sentido. Apaga-se, necessariamente, o processo de deslizamentos contínuos, as falhas: apaga-se o espaço constitutivo do equívoco.

Já o analista precisa se colocar no lugar de quem suspende a evidência do sentido, negando-o como produto de um processo fixo, ou seja, o analista olha para a construção do sentido que se dá constitutivamente sob o efeito metafórico. Isso não significa que o analista possa se colocar fora da ideologia, já que esta exterioridade é ilusória, mas as relações que se dão entre sujeito e linguagem são qualitativamente diferentes e isso produz efeitos. Essa distinção foi de fundamental importância para que eu pudesse amadurecer minha relação com a interpretação (ou, dito de outro modo, com as práticas de leitura e escrita) no espaço escolar.

Outra compreensão teórica de Eni Orlandi que me afetou profundamente foi sua reflexão sobre o silêncio. Diz a autora que a "linguagem supõe a transformação da matéria significante por excelência (o silêncio) em significados apreensíveis, verbalizáveis. Matéria e formas. A significação é um movimento. Errância do sujeito, errância dos sentidos" (ORLANDI, E. 1992, p. 35). Para Eni Orlandi, o "Sentido do silêncio não deriva do sentido das palavras" (ORLANDI, 1992, p. 68). Há, portanto, para a autora, sentido no silêncio. Mas seu sentido é de outra ordem. Essa compreensão não apenas me permitiu tocar de modo mais profundo no funcionamento da linguagem e do discurso, na relação entre o não-sentido e o sem-sentido, quando observamos a diferença elaborada por Orlandi entre o silêncio fundador e o silêncio constitutivo, como também me permitiu compreender o silêncio como resistência. Essa compreensão estabelece possibilidades de ressignificação muito importantes para um espaço como o escolar em que o silêncio é normalmente significado como dificuldade cognitiva ou ausência de vontade, de comprometimento. Permitiu-me, ainda, compreender o semsentido formulando na resistência incansável de sujeitos escolares que estavam no movimento de relação com a língua, mas que tinham esta relação silenciada pela ausência de uma escuta. Um sem-sentido não consentido na insistência de uma projeção imaginária de autoria e de leitura adequadas ao já sabido escolar. 
Se há sentido no silêncio e pode haver sentido também no dizer, fui provocada a procurar compreender melhor o que vinha a ser "fazer sentido". Já naquele momento conseguia antever que "fazer sentido" poderia não coincidir com estar no sentido.

Para essa compreensão, retomei Eni Orlandi (1996, p. 95) e sua reflexão sobre o gesto de interpretação se constituir a partir de uma dupla necessidade: a de que os 'fatos reclamam sentidos' (PAUL-HENRY, 1989) e a de que o homem está condenado a significar. Orlandi dirá que "face a qualquer objeto simbólico, o Sujeito se encontra na necessidade de "dar" sentido. [e a autora pergunta] E o que é dar sentido? [respondendo que] Para o sujeito que fala, é construir sítios de significância (delimitar domínios), é tornar possíveis gestos de interpretação" (ORLANDI, E. 1993c:2). Ainda nas palavras da autora, este é "o cerne do gesto de interpretação, e sua eficácia simbólica", gesto que para Orlandi "é o lugar em que se tem a relação do sujeito com a língua. Esta é a marca da "subjetivação", o traço da relação da língua com a exterioridade (constitutiva)". (op.cit. p. 46). No entanto, nos mostra a autora, esta relação pode se dar de modos distintos, conforme as condições de produção.

Entrava para meu percurso mais um ponto fundamental de compreesão. Estes diferentes modos de a interpretação se instalar tem para Orlandi uma relação com a autoria. Para ela, "a autoria ao mesmo tempo constrói e é construída pela interpretação" (ORLANDI, 1993c:13). E a autoria não está sendo pensada aí como lugar de originalidade. Mas sim de filiação à rede de memória. É por isso que Orlandi (1993c), refletindo sobre a relação da autoria com o interdiscurso, estabelece uma distinção entre o funcionamento de uma repetição empírica, uma repetição formal e uma repetição histórica. $\mathrm{O}$ funcionamento da repetição empírica consiste em um exercício mnemônico e, portanto, não historicizador: sob este funcionamento, o sujeito está no interpretado; o funcionamento da repetição formal consiste na técnica da reprodução de frases produzindo apenas um exercício gramatical que não permite a historização: o sujeito é significado sem que as palavras lhe façam sentido; o funcionamento da repetição histórica permite a inserção do sujeito no interdiscurso: o dizer se inscreve no repetível enquanto memória constitutiva. Ou seja, o sentido sob o efeito do sempre - já - lá (repetível) é posto em funcionamento pelo sujeito, já que este se enreda numa rede de filiações que permite à língua e ao sujeito significarem. Diferenças fundamentais formuladas por Eni Orlandi. Diferenças que me permitiram compreender que à escola cabe construir condições de produção para que a repetição histórica se instale de modo a construir relações de leitura e de escrita de textos em que o sujeito escolar se inscreva no repetível do interdiscurso, fazendo sentido, estando no sentido, no interpretável e não apenas no interpretado. Construindo um lugar de autoria.

Era preciso, assim, compreender melhor o lugar da autoria, o que me foi permitido por meio da formulação de Orlandi (1988), elaborada junto com Guimarães, de que "a função autor se realiza toda vez que o produtor da linguagem se representa na origem, produzindo um texto com unidade, coerência, progressão, não contradição e fim. Em outras palavras, [dizem os autores] ela se aplica ao corriqueiro da fabricação da unidade do dizer comum, afetada pela responsabilidade social: o autor responde pelo que diz ou escreve, pois é suposto estar na origem". A partir desse modo de compreender a função-autor, foi possível que eu trabalhasse na direção de afirmar que é preciso que sejam construídas condições de produção para que esta assunção se constitua, ou seja, para que seja possível se efetivar este efeito de representação do autor enquanto origem e responsável pelo que diz ou escreve. E isso não é possível se o espaço escolar apenas provê o significado, o posto. Porque justamente nega-se aí a atribuição da origem àquele que, por isso mesmo, é limitado a repetir mnemônica ou formalmente. É necessário, pois, um trabalho com a escuta e com a deriva que dê 
movência ao sujeito escolar que aí sim tem condições de circular por diferentes sítios de significância. É preciso, pois, atribuir sentido àquilo que comparece como sem-sentido, apesar das - e em função das - injunções às repetições empíricas e formais. É preciso lidar com o imprevisível.

Isso significaria não se relacionar com a história de leituras de um texto, como tão bem nos mostra Orlandi (1998) quando reflete sobre o leitor? Não. Isso significa que é preciso construir possibilidades de relações com estas histórias de leitura. O posto, o significado, são importantes. Relacionar-se com o posto e o já significado não é da mesma ordem que estar no significado, sem se significar, sem se inscrever no repetível histórico.

$\mathrm{Na}$ esteira dessa compreensão, pensando com Orlandi, foi possível formular a configuração de dois lugares para o sujeito na relação com a interpretação no espaço escolar: o de espaços interpretativos, sob o funcionamento da repetição histórica, na qual os sentidos se constróem; e espaços impermeáveis nos quais os sujeitos movimentam-se à margem dos sítios de significância, sob o funcionamento da repetição formal ou mnemônica, nas quais o sujeito repete sem atribuir sentido.

Era importante, então, insistir na compreensão do efeito de representação da originalidade e não na demanda pela originalidade ou pela criatividade. Foi com Eni Orlandi que pude fazer o fundamental deslocamento entre criatividade e produtividade.

Esta questão percorreu desde o início o trabalho de reflexão da autora ${ }^{3}$, tratando-a através da proposta dos processos de paráfrase e polissemia como constitutivos, ambos, de todo processo de significação: de todo discurso. Eni Orlandi (1998) nos mostra que tomar o sujeito como capaz de criatividade na linguagem pressupõe a não existência de determinação no sujeito. Trabalhando com o sujeito histórico e, portanto, determinado, a autora propõe os processos de paráfrase e polissemia enquanto constitutivos do fazer dizer, deslocando a própria possibilidade de se pensar em termos de originalidade/novidade dos sentidos. Não se trata, pois, de pensar sobre sentidos novos ou velhos, mas de trazer a Diferença como lugar de possibilidade do movimento dos sentidos. A partir desta compreensão, Orlandi propõe a distinção entre Produtividade e Criatividade. O primeiro processo, para a autora, "reconduz todo dizer ao mesmo espaço significante, embora na variedade dessa produção. Já a criatividade é ruptura no processo dominante de produção dos sentidos, apontando para outras posições do sujeito. Estes dois processos andam tão juntos que é impossível separá-los" (1998, p.18), finaliza a autora. Trazendo esta reflexão relativa a processos de significação em geral desenvolvida por Orlandi para a especificidade do lugar da autoria na escolarização, eu pude dizer que não cabe pensar em termos de originalidade do autor, aquele que dirá o novo, mas sim na produtividade da língua, aí pensadas suas contrapartes constitutivas: a repetição e a diferença. Isto é, pensar na produtividade da língua e não na originalidade do autor, desloca a compreensão deste sujeito como intencional, autônomo e cônscio dos sentidos que lhe conformam. Deslocamento que abre espaço para a visibilidade e a compreensão do contínuo movimento entre o mesmo e o diferente, na língua, que possibilita um lugar constitutivo para a resistência do sujeito na história.

Ao lado disso, era preciso levar em consideração que no funcionamento das práticas de ensino de ler e escrever no espaço escolar há um batimento contínuo entre a atualidade e a memória, como nos ensina Pêcheux. E era preciso nunca esquecer que nosso processo de escolarização passa de modo incontornável pelo fato discursivo da colonização. Eu ia compreendendo que, na contínua atualização dessas práticas

3 Entre estes trabalhos, conferir, 1978, 1983 e 1996. 
escolares, há, ressoando (SERRANI, 1993), memórias, ordens de sentido instauradas no gesto da colonização. Essa compreensão se deve, em grande medida, à formulação de Discurso Fundador por Orlandi, entendido como "a fala que transfigura o sem-sentido em sentido" (ORLANDI, E. 1993a , p. 8).

$\mathrm{O}$ processo de transfiguração, para a autora, baseia-se no posicionamento de que as ideias não têm uma origem, nem um lugar fixo, elas estão em contínuo jogo de deslocamento, num processo de cópia, simulação, diferença. Esse jogo é determinado pela história. É na história que vão se construindo os lugares de significação, os lugares das ideias. Esses lugares vão se configurando a partir da relação linguagem/pensamento/mundo, calcada no efeito ideológico de referencialidade direta língua/mundo - o efeito de objetividade e de concretude dessa referência. Este processo é, para Orlandi, um processo de organização dos sentidos (ORLANDI, 1993a). Para a autora, um Discurso Fundador não se instaura num espaço vazio, movimentando inclusive "retalhos" de sentidos que são deslocados. Um Discurso Fundador faz do semsentido, sentido, instaurando-se onde outros sentidos já se instauraram, produzindo uma "nova ordem dos sentidos" (ORLANDI, 1993a).

Uma das características fundamentais do Discurso Fundador, segundo Orlandi, é o efeito do "sempre-já-lá" - evidente e familiar. Assim, o Discurso Fundador instaura uma memória histórica discursiva que repercute seus efeitos continuamente pela linguagem. E essa memória configura sentidos estabilizados conformados como naturais por meio de funcionamentos discursivos.

Um desses funcionamentos, conforme nos mostra Orlandi (1990), é a existência de uma dissimetria entre o leitor brasileiro e o europeu. Essa dissimetria ocorre em função do apagamento indevido de uma diferença necessária existente entre os lugares de leitura do brasileiro e do europeu. Quando a diferença é apagada, cria-se uma falsa igualdade e isto produz efeitos. Essa compreensão é fundamental para uma reflexão discursiva consequente sobre as práticas de leitura e escrita de textos na escola.

Não desenvolverei aqui a questão, mas para dizer o mínimo, a relação de um sujeito escolar brasileiro com a língua portuguesa enquanto objeto de ensino, enquanto língua escolar, é afetada por um sentido inaugural da presença da língua portuguesa como uma língua estrangeira, ao mesmo tempo em que esse sentido é apagado na evidência da língua portuguesa como língua materna, nacional e oficial, sem deixar, contudo, de reverberar sentidos. Lembro aqui mais uma vez o movimento da interpretação tal como formulado por Orlandi, marcado por um duplo trabalho: "no mesmo lugar em que há o equívoco, o outro, há também o trabalho ideológico da estabilização do sentido, trabalho de contenção do movimento de sentidos e de sujeitos" (ORLANDI, 1997). É neste jogo tenso que as práticas pedagógicas se dão. Dar visibilidade a este jogo permite novos gestos de interpretação. É preciso dizer que essa compreensão me permitiu um enorme percurso dentro da História das Ideias Linguísticas. Mas esta já é outra história!

E para fechar esse trajeto, permito-me, como último gesto de homenagem a essa intelectual com tantos atributos incomensuráveis, finalizar a retomada de minha formação com Eni Orlandi, citando meu agradecimento a ela inscrito em minha tese de doutoramento:

[Agradeço]

“À Eni pelo carinho e sensibilidade, pelo respeito, por estabelecer uma relação em que sempre vi aberto o espaço para dizer. Por seu trabalho, construindo um percurso para o meu dizer. Pelo seu companheirismo e compreensão. Pela sua calma e confiança na 
espera de meu trajeto, sempre perto e pronta para me ouvir. Pelos sentidos postos para minha vida intelectual, institucional e da vida-vida."

Obrigada!

\section{REFERÊNCIAS}

ORLANDI, E. A Linguagem e seu Funcionamento. 2a. ed. Ed Pontes, Campinas, 1987.

Discurso e Leitura. Cortez, São Paulo, 1988.

Terra à vista. Ed. Cortez/Ed. da Unicamp, São Paulo/Campinas, 1990.

As Formas do Silêncio. Ed. da UNICAMP, 1992.

- (org.) Discurso Fundador: a formação do país e a construção da identidade nacional. Ed. Pontes, Campinas, 1993a.

Discurso: fato, dado, exterioridade (mimeo), $1993 b^{4}$.

Autoria e Interpretação (mimeo), 1993c.

Leitura como Dispositivo Teórico (mimeo), 1993d.

Interpretação; autoria, leitura e efeitos do trabalho simbólico. Ed Vozes, Campinas, 1996.

A leitura e os leitores. Ed. Pontes, Campinas, 1998.

Recebido em: agosto de 2017.

Aprovado em: outubro de 2017.

Como citar este trabalho:

PFEIFFER, C. C. Instauração de um lugar de pesquisa, de uma posição pesquisadora tributo a Eni Orlandi. Traços de linguagem, v. 2, n. 1, p. 29-35, 2018.

\footnotetext{
${ }^{4}$ Sempre foi muito próprio de Eni Orlandi proporcionar a seus orientandos os textos que ela apresentava em eventos ou que havia submetido à publicação, mas ainda não haviam sido publicados. Este e os dois seguintes, me chegaram pelas mãos de Eni antes de sua publicação no livro que sairia em 1996, de fundamental importância em minha trajetória e para a Análise de Discurso: Interpretação: autoria, leitura e efeitos do trabalho simbólico (1a. edição: 1996, Ed. Vozes).
} 